\title{
Keraton Yogyakarta Masa Lampau dan Masa Kini: Dinamika Suksesi Raja-Raja Jawa dan Politik Wacana "Raja Perempuan"
}

\author{
Ilmiawati Safitri \\ Program Studi S2 Ilmu Sejarah, Fakultas Ilmu Budaya, \\ Universitas Gadjah Mada
}

Alamat korespondensi: ilmiawatisafitri@gmail.com

\begin{abstract}
This article presents the dynamics of the succession of the king's regime in the Yogyakarta palace, which entered the crisis period because of the absence of successors to the male king. The emergence of the queen discourse that echoed at the Yogyakarta palace since 2010. It has sparked new tensions for the relatives of the palace. This discussion continues to grow. The words of the king echoed by Sultan Hamengku Buwono (HB) X under the pretext of gender became political ambition to perpetuate power. This study used the historical method to answer the problems that in every change of regimes in the Sultan Palace, Yogyakarta was always followed by conflicts over the throne and tug of war which affected the people outside the palace, such as when Islamic Mataram broke into four kingdoms. At that time, the community took part in regional warfare. This impact arose because of the desires of every descendant of the king, who feels entitled to become the next king.
\end{abstract}

Diterima/ Received: 11 Mei 2019

Disetujui / Accepted: 4 Juli 2019
Keywords: Yogyakarta Palace; King Successions; Sultan HB X; Queen.

\begin{abstract}
Abstrak
Artikel ini menganalisis dinamika suksesi kepemimpinan raja di Keraton Yogyakarta yang masuk pada masa krisis karena ketiadaan penerus raja laki-laki. Kemunculan wacana "raja perempuan" yang menggema di Keraton Yogyakarta sejak 2010 memantik ketegangan baru bagi kerabat keraton. Wacana yang muncul pada 2010 ini terus berkembang. Sabda raja yang dikumandangkan Sultan Hamengku Buwono (HB) X dengan dalih gender sesungguhnya merupakan sebuah ambisi politik guna melanggengkan kekuasaan. Dengan menggunakan metode sejarah, artikel ini menjawab bahwa dalam setiap pergantian kekuasaan di Keraton Yogyakarta selalu diiringi konflik perebutan tahta dan tarik ulur kepentingan yang berdampak pada masyarakat di luar keraton, seperti ketika Mataram Islam pecah menjadi empat kerajaan. Pada saat itu, masyarakat ikut andil dalam perang perebuatan wilayah. Dampak ini timbul karena keinginan setiap keturunan raja yang merasa berhak menjadi raja selanjutnya.
\end{abstract}

Kata Kunci : Keraton Yogyakarta; Suksesi Raja; Sultan HB X; Raja Perempuan. 


\section{Pendahuluan}

Legitimasi suatu kekuasaan adalah suatu alasan pembenar bagi seseorang atau suatu kelompok untuk memegang dan menggunakan kekuasaannya terhadap orang atau kelompok lain. Dengan demikian, legitimasi merupakan prasyarat yang tidak dapat diabaikan, baik oleh seseorang maupun sekelompok orang yang hendak berkuasa. Ringkasnya, legitimasi menjadi prasyarat sekaligus jaminan yang menopang keberadaan serta pemberlakuan sebuah kekuasaan (Berlian, 2002: 238). Jika menuntut kehidupan yang ideal, maka semestinya manusia hidup dalam kesetaraan. Namun demikian, harus diakui bahwa legitimasi telah menciptakan hubungan yang tidak seimbang.

Dibebani oleh godaan-godaan kekukasaan tanpa batas, serta tanggung jawab tunggal dan luas untuk memertahankan ketertiban dunia, maka kedudukan raja haruslah diisi oleh seseorang yang memiliki keunggulan dan kecakapan luar biasa. Orang Jawa beranggapan bahwa keunggulan yang demikian harus nyata dalam sinar cahaya wajah raja. Seorang raja yang buruk bahkan sering kali dianggap cacat. (Moertono, 1985, p. 47). Di Jawa, kedudukan raja sering diabsahkan dengan membuktikan kesinambungan. Hubungan darah dengan seorang pendahulu yang agung, memungkinkan seseorang ikut mendapatkan aura keagungan. Kedatangan Islam tidak menghilangkan kebiasaan membuktikan kesinambungan melalui kekerabatan, dan ini diperkuat dengan kehadiran budaya Arab yang menggabungkan nama seorang leluhur dengan namanya sendiri (Moertono, 1985, p. 62).

Dalam penulisan artikel ini, penulis memiliki dua pertanyaan kritis yang muncul dari peristiwa lampau dan peristiwa kontemporer yang terjadi di tanah Yogyakarta. Pertama, Bagaimana bentuk dinamika suksesi para raja Kesultanan Yogyakarta dari masa ke masa? Kedua, Bagaimana tanggapan masyarakat dan dampak sosial politik warga Yogyakarta terhadap munculnya wacana "Raja Perempuan". Menggunakan pendekatan ilmu politik, tulisan ini menganalisis peristiwa pemberian gelar baru bagi GKR Pembayun yang sekaligus menandakan pengangkatannya sebagai Putri Mahkota Keraton Yogyakarta dengan mengaitkan terhadap kemungkinan konsep kuasa Jawa, khususnya pada peran dan posisi perempuan Jawa kontemporer.

\section{Keraton Masa Lampau, Suksesi Raja-Raja Yogyakarta dari Masa ke Masa Lahirnya Kesultanan Yogyakarta dan Kasunanan Surakarta Pasca-Perang}

Perang Suksesi III atau disebut juga dengan Perang Mangkubumi (1746-1755) dapat dipandang sebagai kelanjutan peristiwa Geger Pecinan, yaitu pemberontakan yang dilakukan oleh orang-orang Cina terhadap Verenigde Oost-Indische Compagnie (VOC). Pemberontakan ini bermula di Batavia, lalu meluas hingga ke Kerajaan Mataram (Supariadi, 1998, p. 2). Perang Suksesi III yang berkecamuk selama hampir 10 tahun ini mengakibatkan terpecahnya Kerajaan Mataram Islam menjadi dua melalui Perjanjian Giyanti, yaitu Kesultanan Yogyakarta dan Kasunanan Surakarta. Kejadian ini dikenal pula dengan sebutan Palihan Nagari.

Peristiwa Palihan Nagari ternyata bukan akhir dari perpecahan Kerajaan Mataram. Dua tahun setelah Perjanjian Giyanti diratifikasi, tepatnya pada 17 Maret 
1757, kembali ditandatangani suatu perjanjian damai antara Sunan Pakubuwono III dengan Raden Mas Said ${ }^{1}$. Raden Mas Said mendapatkan gelar Mangkunegara I. Ia mendapat wilayah kekuasaan baru yaitu berupa tanah lungguh seluas 4.000 karya, serta mendapat hak khusus untuk menyelenggarakan kegiatan upacara kerajaan. Penerimaan kedua pihak terhadap perjanjian damai, sekaligus menjadi tanda bahwa pengaruh VOC dalam urusan intern keraton semakin kuat. Tindakan VOC bahkan tidak hanya berhenti sebagai pencetus gagasan saja, melainkan juga berperan aktif sebagai perantara, sehingga dalam sumber tradisional dituliskan bahwa VOC merupakan Ingkang Minangka Dalang (Soekanto, 1952, p. 5).

Pemilihan nama dan gelar bagi masing-masing raja juga tidak luput dari perebutan. Pada awalnya, raja Mataram menggunakan gelar Panembahan, Sultan, dan Sunan. Raja pertama yang menggunakan gelar sultan adalah Sultan Agung Hanyokrokusumo (1613-1645). Sultan Agung mengirimkan utusan ke Makkah guna meminta gelar sultan pada Ulama Makkah untuk melegitimasi kekuasaannya. Beberapa sejarawan mengatakan jika Sultan Agung termotivasi mengislamkan gelarnya karena sering muncul perselisihan antarpemeluk Hindu dan Islam. Sebagai penguasa tertinggi di tanah Mataram, Sultan berkewajiban sebagai penata agama dan wakil Allah, sehingga gelarnya adalah Sayyidin Pantogomo Khalifatullah. Namun raja penggantinya, Amangkurat I hingga III tidak melanjutkan gelar Sultan dalam kepemimpinannya. Begitu pula Pakubuwono yang memilih menggunakan gelar Susuhunan atau Sunan. Maka setelah Perjanjian Giyanti, gelar Khalifatullah melekat pada Sultan Yogyakarta dan Sunan pada Surakarta (Fuhaidah, 2015, p. 3).

\section{Konflik Elite dalam Konteks Pergantian Tahta}

G. Moedjanto menjelaskan konsep kekuasaan raja-raja Mataram (1575-1755) bersifat absolut, yang tergambar dalam konsep keagung-binataran. Hal itu berarti bahwa kekuasaan raja sangat besar "wenang wisesa ing sanagari" (berwenang tertinggi di seluruh negeri), tetapi harus pula diimbangi dengan kewajiban yang besar (Moedjanto, 1987, p. 77-78). Di puncak tertinggi, tangga bangsawan-bangsawan Jawa adalah raja (Sultan dan Susuhunan), yang melegitimasi kekuasaannya dengan mengaku memiliki sebuah posisi sakral (kasekten). Idealnya, seorang raja tidak ikut campur dalam urusan-urusan negara. Akan tetapi, pada praktiknya hal ini berbeda antara satu penguasa dengan penguasa yang lain. Pengelolaan harian kerajaan diserahkan kepada perdana menteri (patih), yang setelah tahun 1743 mengabdi kepada penguasa Jawa dan penguasa Belanda (Houben, 2002, p. 12-13).

Dalam kaitan dengan Kerajaan Mataram ada dua penyebab utama perubahan yang harus diperhitungkan, yaitu penyebaran Islam dan kehadiran VOC, yang pada mulanya berjalan berdampingan, namun kemudian mengungguli dan akhirnya

\footnotetext{
${ }^{1}$ Raden Mas Said adalah putera Pangeran Mangkunegara Kendhang dan cucu Raja Amangkurat IV. Raden Mas Said yang nantinya bergelar Mangkunegara I ini melakukan perlawanan terhadap Pakubuwono II karena ia tidak setuju dengan perlakuan Pakubuwono II yang mudah terhasut oleh VOC. Pakubuwono II juga dianggap lemah dan tidak dapat memimpin kerajaan.
} 
merebut kekuasaan. Sejak kedatangan VOC ke Tanah Mataram, disusul Inggris, lalu digantikan oleh Pemerintah Kolonial Belanda, keadaan keraton semakin rumit. Campur tangan pihak asing selalu menjadi pemicu perpecahan dan permusuhan antarkerabat keraton. Selain itu, dalam disertasinya Darsiti Suratman juga menuliskan bahwa penyebab penyusutan atau erosi kekuasaan raja adalah faktor intern keraton. Perebutan tahta kerajaan selalu menjadi masalah, yaitu ketika raja yang berkuasa mangkat. Pascakemangkatan seorang raja, sering kali terjadi peristiwa-peristiwa yang tidak diharapkan dan berkembang menjadi perang suksesi (Suratman, 1989, p. 425). Tujuannya tidak lain untuk mendapatkan atau mempertahankan tahtanya. Bukan menjadi rahasia umum apabila sang raja atau pangeran meminta bantuan kepada VOC yang memiliki kekuasaan militer. Kesempatan ini tentu dimanfaatkan sebaikbaiknya oleh pihak VOC, dan dilanjutkan oleh Pemerintah Kolonial Hindia Belanda. Namun kemudian, oleh pihak kolonial, lingkup kekuasaan raja dipersempit, sehingga tidak terasa habislah kekuasaan raja menurut konsep politik.

\section{Suksesi Raja-Raja di Kesultanan Yogyakarta}

\section{Rumitnya Perputaran Kekuasaan dari Sultan HB II ke HB III}

Raden Mas Sundoro atau Raden Mas Timur terpilih menjadi putra mahkota saat ia berusia sepuluh tahun, dengan gelar Kanjeng Pangeran Adipati Anom Hamengkunegara Sudibya Raja Putra Nalendra Mataram. Pada 24 Maret 1792, sang ayah, yaitu Sultan HB I wafat (Darmasastri, 2006, p. 41). Raden Mas Sundoro diangkat menjadi raja selanjutnya dengan gelar Sri Sultan HB II. Ia dikenal sebagai raja yang keras dan anti terhadap Belanda. Oleh sebab itu, masa pemerintahan Sultan HB II menjadi salah satu periode pemerintahan yang paling bergolak. Konflik-konflik yang terjadi di antara para putra Mangkubumi dan orang-orang Eropa menghiasi jalannya pemerintahan sultan.

Berbeda dari sikap yang ditunjukkan oleh Sultan HB I yang bersedia bekerja sama dengan pihak Belanda, Sultan HB II menolak dengan tegas campur tangan lebih besar dari pihak asing, baik Belanda maupun Inggris. Sutan HB II tidak menganggap Belanda sebagai kekuatan yang harus diperlakukan dengan hati-hati. Situasi dalam keraton menjadi semakin pelik. Pasalnya, Sultan HB II mengganti sebagian penasihat raja pada masa Sultan HB I, padahal para pengganti tidak cakap dalam mengatasi permasalahan pemerintahan dalam keraton. Salah seorang di antara penasihat keraton yang dipilih oleh Sultan HB II adalah Patih Danureja II, cucu Patih Danureja I (1755-1799). Namun demikian, keputusan untuk memilih Patih Danureja II ini ternyata sangat merugikan keraton, karena sang patih justru berbalik mendukung Belanda.

Dukungan yang lemah dari orang-orang di sekitar raja rupanya membuat Pemerintah Kolonial Belanda berkeinginan mengganti kedudukan Sultan HB II dengan putra mahkota yang dipandang lebih lunak dan mudah diajak bekerja sama. Hal ini bemula ketika terjadi pertikaan antara sang raja dengan Belanda pada 28 Juli 1808. Pada waktu itu, Daendels mengumumkan suatu peraturan baru mengenai upacara penerimaan wakil bangsa Belanda di dalam keraton. Peraturan tersebut 
dibuat Daendels dengan tujuan agar tercapai kesetaraan derajat antara residen Belanda sebagai wakil Raja Louis dari Belanda dengan penguasa Jawa. Namun demikian, hanya Susuhanan dari Kasunanan Surakarta yang menerima dan menjalankan peraturan dari Daendels tersebut, sedangkan Sultan HB II menolaknya. (Darmasastri, 2006, p. 51). Ia beranggapan bahwa peraturan baru tersebut adalah bentuk penghinaan terhadap kedudukannya.

Pada 30 Desember 1810 Daendels bergerak menuju Yogyakarta dengan membawa 3.200 serdadu dan memaksa Sultan HB II turun tahta untuk kemudian menyerahkan tahta kepada putranya yang kini menjadi wakil raja. Selain itu,, sultan juga dituntut untuk membayar sebanyak hampir setengah juta gulden sebagai uang tebusan bagi pasukan Daendels. Setelah peristiwa penyerbuan tersebut, Sultan HB II masih diperbolehkan tinggal di keraton dan berganti nama menjadi Sultan Sepuh. Akan tetapi, pemerintahan baru ini tidak berlangsung lama karena pada akhir September 1811, Sultan HB II berhasil merebut kembali tahta pemerintahan (Sumbogo, 2000, p. 42-43).

Pada pemerintahannya yang kedua, Sultan HB II kembali menghadapi masalah dengan penguasa baru, yaitu Thomas Stanfford Raffles (1811-1816). Tidak jauh berbeda dengan Daendels, Raffles juga menentang feodalisme. Pada mulanya, Raffles tidak ambil masalah dengan Sultan HB II. Namun ternyata, secara diam-diam Sultan HB II berkoordinasi dengan Kasunanan Surakarta untuk mengumpulkan militer guna menyerang pasukan Inggris. Hubungan rahasia ini diketahui oleh pihak Inggris berkat mata-mata Pangeran Natakusuma yang telah dijadikan sekutu Inggris di dalam Keraton Yogyakarta. Hingga akhirnya, pada Juni 1812, Raffles memutuskan untuk menyerbu Keraton Yogyakarta karena usahanya untuk bekerja sama dengan Sultan HB II ditolak. Penyerbuan ini dilakukan oleh 1200 prajurit Eropa dan Sepoy (India) serta didukung 800 prajurit Legiun Mangkunegaran. Peristiwa ini kemudian dikenal dengan peristiwa Geger Sepoy (Darmasastri, 2006, p. 55-56).

Dampak dari peristiwa Geger Sepoy ini sangat merugikan Kesultanan Yogyakarta. Keraton dirampok dan dijarah oleh orang-orang Inggris. Selain kehilangan harta, keraton juga kehilangan naskah berharga. Tidak hanya itu, uang perbendaharaan milik keraton juga dikuasai dan diambil oleh Raffles. Beberapa literatur menuliskan bahwa uang yang diambil adalah sebesar 500.000 Gulden (M.C Ricklefs, 2005, p. 250). Sultan HB II kemudian ditangkap dan menjalani hukuman pengasingan di Pulau Penang bersama dengan putranya, yaitu Pangeran Mangkudiningrat (Carey, 1985, p. 11). Pasca-Geger Sepoy, Pangeran Natakusuma yang membantu pihak Inggris dihadiahi wilayah kekuasaan seluas 4.000 cacah di kawasan Yogyakarta. Ia juga mendapat gelar baru, yaitu Pakualam I dengan kerajaan baru yang bernama Pura Pakualam.

Setelah diasingkan di Pulau Penang, Sultan HB II dipindahkan ke Jakarta selama satu tahun, untuk kemudian dipindahkan ke Ambon (1816-1826). Di usianya yang ke76, Sultan HB II dipulangkan dan diangkat kembali menjadi raja hingga akhir hayatnya (1826-1828). Sultan HB II atau dikenal sebagai Sultan Sepuh merupakan raja yang paling kontroversial, karena menjadi satu-satunya raja Yogyakarta yang 
dinaikkan ke tahta tiga kali berturut-turut sebagai akibat dari kisruh politik internal keraton. Meskipun demikian, Sultan HB II tetaplah raja besar, dengan sifat "kepala batu" sebagaimana julukan yang diberikan Belanda. Ia mewariskan sifat ksatrianya pada keturunannya. Ia pula satu-satunya raja Yogyakarta yang tidak dimakamkan di kompleks pemakaman sakral Raja-raja Mataram, di Bukit Imogiri.

\section{Gambar 1. Pasang Surut Suksesi Politik Keraton Yogyakarta 1812-1828}

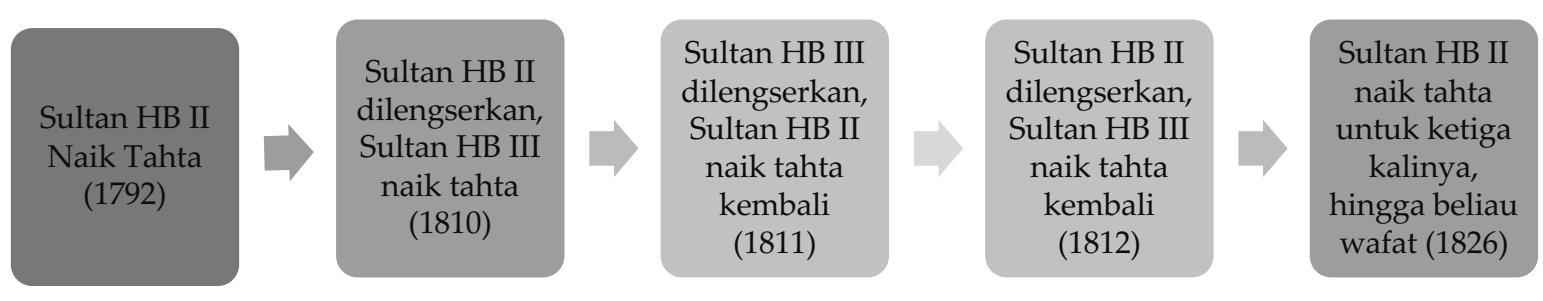

Sumber: Purwadi, 2007.

\section{Sultan HB V, Raja Tanpa Putera Mahkota}

Sultan HB V memiliki nama kecil G.R.M. Gathot Menol. G.R.M. Gathot Menol dinobatkan sebagai raja di usianya masih sangat muda, yaitu tiga tahun. Pada saat naik tahta, G.R.M. Gathot Menol didampingi oleh Dewan Perwalian yang terdiri atas neneknya, ibunya, Pangeran Mangkubumi (putra Sultan HB II), dan Pangeran Diponegoro (anak Sultan HB III) karena masih balita. Beberapa sejarawan mengatakan bahwa salah satu penyebab dari Perang Diponegoro adalah penobatan Sultan HB V tanpa memedulikan hak-hak Pangeran Diponegoro. (Purwadi, 2007, p. 445-447).Hal itu lah yang ditengarai menjadi penyebab, Pangeran Diponegoro mundur dari jabatannya sebagai Dewan Perwalian, dan mulailah Diponegoro dibantu Kyai Mojo serta Sentot Prawirodirdjo melakukan perlawanan terhadap kolonial.

Kehidupan Sultan HB V dianggap sebagai kehidupan raja yang paling dramatis. Ketika ia dinobatkan sebagai raja, tahtanya sempat "diambil" oleh pendahulunya yaitu Sultan HB II atas campur tangan Belanda. Sultan HB II sebenarnya masih menjalani masa pengasingan di Ambon. Belanda sengaja memulangkannya agar dapat berkuasa kembali dengan misi khusus yang telah mereka rencanakan. Setelah SultanHB II wafat, HB V kembali naik ke singgasana raja pada 1828. Akan tetapi, pada masa pemerintahannya, sang raja kehilangan banyak dukungan, baik dari internal keraton maupun sebagian rakyat Yogyakarta (https://irto.id/mk-putuskan-sultanperempuan-bisa-jadi-gubernur-diy-cvGN, diakses 17 Oktober 2018).

Harus diakui bahwa pengaruh Pemerintah Kolonial Belanda sangat kuat dalam suksesi paksa ini. Saat itu, Belanda menggunakan "akal bulusnya" dan berusaha memecah belah internal keraton serta rakyat Yogyakarta. Selain karena Sultan HB V dinilai kurang cakap dan masih terlalu muda, Belanda juga membutuhkan Sultan HB II untuk memecah dukungan rakyat Yogyakarta dalam Perang Diponegoro, karena sebagian besar rakyat Yogyakarta mendukung Pangeran Diponegoro. 
Pada 28 Maret 1830, De Kock berhasil menangkap Pangeran Diponegoro di Wisma Keresidenan Kedu. Selanjutnya, Pangeran Diponegoro bersama beberapa pengikutnya dibawa ke Semarang, kemudian dibawa ke Batavia untuk diasingkan ke Manado. Sampai akhirnya, sang pangeran wafat di Makassar pada 8 Januari 1855 (https://www.kratonjogja.id/raja-raja/6/sri-sultan-hamengku-buwono-v, diakses pada 17 Oktober 2018).

Sang Sultan yang lahir pada 1821 ini wafat pada 5 Juni 1855 dalam usia 34 tahun. Pada saat itu, G.K.R. Kencono sebagai permaisuri pertama belum memiliki putra. Sementara itu, permaisuri kedua, yaitu G.K.R. Sekar Kedaton yang sedang hamil juga belum menunjukkan tanda-tanda kelahiran. Maka dari itu, untuk kali pertama, tahta kerajaan diserahkan kepada adik kandung Sultan HB V yang bernama Raden Mas Mustojo.

Pada 15 Julli 1855, Raden Mas Mustojo dinobatkan menjadi raja selanjutnya yang bergelar Sultan HB VI. Meskipun Sultan HB VI bukan putera kandung dari raja sebelumnya, ia mendapatkan dukungan penuh dari kalangan bangsawan di Yogyakarta. Oleh sebab itu, setelah mendapat persetujuan dari pihak kolonial, Raden Mas Mustojo tanpa ada halangan dilantik menjadi raja (Sesana, 2010, p. 31).

Guna mencegah hal-hal yang tidak diinginkan, seperti pertumpahan darah karena perebutan tahta, Sultan HB VI segera menetapkan putra mahkotanya pada 1872. Akan tetapi, ternyata tidak semua hal berjalan sesuai rencana. Raden Mas Mohammad, putra Sultan HB V yang lahir pada 17 Juni 1855 atau 14 hari setelah Sultan HB V wafat meminta agar dirinyalah yang dinobatkan menjadi raja selanjutnya. Permintaan itu kemudian memicu konflik internal di Keraton Yogyakarta, yang dikenal dengan Peristiwa Suryangelangan. Akhirnya, Permaisuri dari Sultan HB V yaitu Ratu Sekar Kedaton dan Raden Mas Mohammad diasingkan ke Manado hingga akhir hayatnya.

\section{Konflik Perpindahan Kekuasaan Sultan Hamengku Buwono VII ke HB VIII}

Sultan Hamengku Buwono VII lahir pada 4 Februari 1839 dengan nama G.R.M. Murtedjo. Setelah sang ayah wafat, Sultan HB VII semakin ditekan oleh pihak kolonial untuk menandatangani berbagai perjanjian yang telah dipersiapkan oleh penguasa Hindia Belanda. Kenaikan tahta Sultan HB VII pada 1877 berlangsung hampir bersamaan dengan kenaikan tahta K.G.P.A. Paku Alam V yang dinobatkan setahun kemudian. Hal ini berarti bahwa kedua wilayah kekuasaan raja-raja ini, yang secara administratif merupakan wilayah pemerintahan Residen Yogyakarta, sudah siap menerima rencana pembaharuan yang dikonsepkan oleh pemerintah kolonial, khususnya dalam bidang hukum dan keamanan (Sesana, 2010, p. 39).

Sultan HB VII memiliki 21 istri serta memiliki 78 anak yang terdiri atas 31 putra dan 47 putri. Pada 1872-1883, G.K.R. Kencono yang merupakan permaisuri sultan harus dilengserkan dan menjadi bergelar G.K.R. Wandhan. Selanjutnya, kedudukan permaisuri digantikan oleh GKR Hemas yang memiliki lima putra dan enam putri. Putra laki-laki pertama bernama G.R.M. Akhadiyat yang ketika berusia sembilan tahun diangkat menjadi putra mahkota (Margana et al., 2016, p. 43). 
Dalam tradisi raja-raja Jawa, sejak masa dinasti Mataram Islam, penunjukan putra mahkota memang tidak selalu dilakukan oleh raja menjelang akhir hayatnya, atau akhir kekuasaannya. Justru sebaliknya, untuk memperkuat posisinya, raja-raja Jawa sering kali menyiapkan putra mahkota pada masa puncak kekuasaannya. Setidaknya, hal ini memiliki dua manfaat; pertama, untuk mencegah terjadinya intrikintrik di kemudian hari;. kedua, untuk memperkuat posisi raja sendiri dan dinastinya, karena jika status pewaris tahta jelas, maka dukungan kesetiaan dan kepatuhan di kalangan para pendukung putra mahkota akan dijamin (Sesana, 2010, p. 67).

Pada 1892, G.K.R. Hemas wafat. Setahun kemudian, sang putra mahkota yang masih berusia 17 tahun dan belum menikah juga wafat. Peristiwa ini tentu menimbulkan pergolakan di kalangan elite keraton. Ratu Kencono sebagai permaisuri kedua meminta agar putranya, yaitu Pangeran Mangkukusumo diangkat menjadi pengganti Pangeran Akhadiyat. Namun demikian, Sultan HB VII tidak mengabulkan permintaan tersebut atas pertimbangan karena G.K.R. Kencono berstatus sebagai permaisuri kedua. Atas dasar pertimbangan itu, Sultan HB VII tetap menunjuk putranya dari Ratu Hemas yang bernama Raden Mas (R.M.) Juminah menjadi pewaris tahta.

R.M. Juminah yang bergelar Pangeran Adipati Anom Hamangkunagoro dikenal sebagai seorang pemuda yang pandai dan kritis. Pada mulanya, pihak kolonial menganggap hal ini menguntungkan karena sang putra mahkota masih remaja, sehingga mudah diajak bekerja sama. Namun di luar dugaan, Pangeran Juminah ternyata mempelajari pasal-pasal yang dimuat dalam verklaring atau kontrak yang diajukan oleh Pemerintah Kolonial Belanda dengan seksama. Ia lantas menolak kontrak yang antara lain berisi (1) Pemberian hak bangun (opstalrecht) kepada pemerintah kolonial; (2) Pengambilalihan hak dari penguasa lokal bagi monopoli penjualan garam; (3) Candu di wilayah kesultanan diganti menjadi kompensasi tahunan; (4) Ketentuan lebih longgar tentang sewa tanah bagi perkebunan (onderneming) dan (5) Kesanggupan pewaris tahta untuk tidak memungut pajak baru. Kekecewaan pihak Belanda terhadap Pangeran Juminah berujung pada usaha untuk menurunkan sang pangeran dari tahtanya. Usaha yang dilakukan oleh Pemerintah Kolonial Belanda salah satunya adalah dengan menghasut Sultan HB VII agar menurunkan sang putra dari tahtanya atau kemudian dikenal dengan "politik adu domba". Pemerintah Kolonial Belanda rupanya berhasil menghasut sultan. Pada 1902, Pangeran Juminah diturunkan dari kursi putra mahkota. Berkali-kali gagal dalam menentukan putra mahkota yang menjadi pewaris kerajaan, Sultan HB VII akhirnya menunjuk RM Putro adik kandung G.R.M. Juminah sebagai putra mahkota. Pemerintah Kolonial Belanda berharap persoalan verklaring dapat diselesaikan ketikan R.M. Putro beranjak dewasa, terlebih pada 1911 diumumkan peraturan baru mengenai kontrak politik. Namun demikian, harapan itu pupus ketika diketahui R.M. Putro sering sakit dan kesehatannya terus menurun. Pemerintah Hindia Belanda yang mendengar kabar tersebut kemudian mengupayakan pengobatan medis. Akan tetapi, upaya itu tidak membuahkan hasil, hingga akihrnya R.M. Putro wafat pada 20 Februari 1913 (Sesana, 2010). 
Keinginan Hindia Belanda untuk segera menguasai garam yang ada di Kesultanan Yogyakarta melalui penandatanganan verklaring oleh putra mahkota, memaksa Sultan HBVII segera menentukan pengganti RM Putro. Liefrinck (Residen Belanda) berusaha membujuk sultan agar mengangkat Pangeran Mangkukusumo, putra dari Ratu Kencono (permaisuri kedua). Namun demikian,Sultan HB VII menolak. Penolakan tersebut masi berdasar pertimbangan yang sama, yaitu status Ratu Kencono sebagai permaisuri kedua. Keteguhan hati Sultan HB VII ini membuat kursi putra mahkota kosong hingga 1915. Banyak permasalahan yang terjadi setelah R.M. Putro wafat, salah satunya adalah calon putra mahkota selanjutnya, yaitu Pangeran Puruboyo yang dituduh mencuri uang, sehingga menyulut kemarahan Sultan HB VII. Hal ini merupakan kesempatan emas bagi Ratu Kencono dan R.M. Mangkukusumo guna menggantikan Puruboyo. Sultan HB VII hampir saja mengangkat Mangkukusumo sebagai putra mahkota. Akan tetapi, keputusan itu tidak langsung disetujui oleh Gubernur Jenderal Hindia Belanda karena mereka mencium ada sesuatu yang tidak wajar. Pada akhirnya, Pangeran Puruboyo memang ditakdirkan untuk menggantikan ayahnya. Pada 13 Juli 1924, ia dikukuhkan menjadi putra mahkota. Namun demikian, Residen Bijleveld mengusulkan kepada Sultan HB VII agar Puruboyo melanjutkan pendidikan ke luar keraton. Sultan HB VII memberikan izin kepada Puruboyo berangkat ke Belanda, untuk melanjutkan pendidikan sekaligus mempersiapkan diri menjadi pewaris tahta.

Sementara sang putra menuntut ilmu di Negeri Belanda, Sultan HB VII merasa sangat tertekan dengan kebijakan Pemerintah Kolonial Belanda yang dirasa semakin mengurangi wewenang dan kewibawaannya sebagai raja. Berbagai permasalahan datang silih berganti, baik yang bersifat kenegaraan maupun kekeluargaan, termasuk persoalan putra mahkota dan para permaisuri. Dalam bidang politik dan pemerintahan, Sultan HB VII menyadari bahwa dirinya semakin tidak bebas membuat kebijakan. Hal itu terjadi karena birokrasi kolonial semakin mendominasi wilayah kerajaannya. Namun demikian, ambisi untuk menjadi seorang raja yang besar dan berwibawa masih tinggi. Hal itu kemudian diwujudkan dengan memberikan perhatian pada bidang kesenian dan kebudayaan.

Pada Desember 1920, kondisi fisik Sultan HB VII semakin menurun. Beberapa pejabat Belanda di Batavia yang telah menyiapkan rancangan verklaring dan akta van verband untuk ditandatangani oleh pewaris tahta dan calon raja baru kemudian berinisiatif memanggil Puruboyo untuk pulang ke Yogyakarta. Rancangan upacara pergantian tahta juga telah disiapkan. Demikian Sultan HB VII berada di akhir kepemimpinannnya. Sebelum wafat, Sultan HB VII secara resmi digantikan oleh RM Puruboyo (Sesana, 2010). Peristiwa penurunan Sultan ini hampir serupa dengan yang terjadi dengan Sultan HB II, yaitu lengser keprabon

\section{Dinamika Polemik Keraton Masa Kini}

Dalam silsilah raja-raja di Kesultanan Yogyakarta belum pernah didapati seorang Ratu (raja perempuan). Sistem patrimonial yang diaplikasikan pada pewarisan tahta kerajaan ini menggunakan sistem pewarisan tahta menurut garis ayah, yang lebih 
mementingkan laki-laki daripada perempuan sebagai pewaris tahta. Raja adalah seorang bapak, mulia, memiliki kuasa seperti dewa, sumber segala kebaikan, kemakmuran, keadilan, kesejahteraan, dan pelindung semua orang sebagaimana tercantum dalam Babad Tanah Djawi, Serat Tjentini, dan Serat Wulangreh (Dewi, 2017, p. 67). Demikian tradisi yang telah mengakar di Kesultanan Yogyakarta, sehingga ketika Sultan HB X mengangkat putrinya, yaitu G.K.R. Pembayun menjadi putri mahkota dengan gelar G.K.R. Mangkubumi muncul protes dari berbagai kalangan. Keputusan berani itu dianggap sesuai dengan tradisi dan sejarah Kesultanan Yogyakarta, sehingga menyebabkan polemik terutama di kalangan bangsawan.

Seperti yang kita ketahui bahwa Yogyakarta merupakan daerah istimewa yang sah sejak masa awal kemerdekaan. Keistimewaan Yogyakarta semakin kuat setelah UU No. 13 Tahun 2012 tentang Kesitimewan DIY dikeluarkan. Seiring dengan pengakuan masyarakat mengenai keistimewaan Yogyakarta, Keraton Yogyakarta menetapkan semacam paugeran (konstitusi) yang menyatakan bahwa gubernur atau raja adalah seorang laki-laki keturunan raja yang bertahta sebelumnya. Hal ini tercantum dalam UU No.13 tahun 2012 pasal 18 ayat 1 tentang pengisian jabatan gubernur dan wakil gubernur yang berbunyi "menyerahkan daftar riwayat hidup dengan melampirkan riwayat pendidikan, pekerjaan, saudara kandurng, istri, dan anak". Jika melihat pasal tersebut, maka dapat kita ketahui bahwa seharusnya yang menjadi gubernur adalah laki-laki.

Polemik di atas muncul karena Sri Sultan HB X tidak memiliki anak laki-laki. Oleh karena itu, kemudian dibuat Raperdais (Rancangan Peraturan Daerah Istimewa) Nomor 2 Tahun 2015 yang berisi tata cara pengisian jabatan gubernur, khususnya persyaratan pengisian jabatan. Pada pasal 3 ayat (1) huruf (m) disebutkan bahwa syarat menjadi gubernur adalah "menyerahkan daftar riwayat hidup yang memuat, antara lain riwayat pendidikan, pekerjaan, saudara kandung, dan anak" (UndangUndang Nomor. 13 Tahun 2012 tentang Keistimewaan Daerah Istimewa Yogyakarta).

Kemunculan sabda raja sebanyak empat kali berturut-turut ini merupakan dampak dari kegelisahan Sultan HB X yang merasa sulit menobatkan G.K.R. Pembayun menjadi putri mahkota. Dalam catatan sejarah, suksesi Raja Mataram belum pernah ada Sultan perempuan. Jika seorang sultan tidak memiliki putra lakilaki maka yang berhak mewarisi tahta adalah adik laki-laki sultan. Namun demikian, jika dilihat dari kacamata politik keraton, sebenarnya yang membuat sulit penobatan putri mahkota adalah masalah paugeran. Oleh sebab itu, Sultan HB X harus menggunakan kekuasaan dan kewenangannya untuk mengubah Paugeran Keraton demi memudahkan penobatan putri sulungnya.

Menurut para pengamat politik keraton, ada dua penghalang utama dari dalam keraton yang harus diterobos oleh Sultan HB X sebelum menobatkan putrinya menjadi putri mahkota. Pertama, Sultan HB X harus memensiunkan keris Ki Ageng Kopek dan Keris Joko Piturun. Keris dalam konsep kekuasaan Jawa bukan hanya sebagai senjata sang raja, tetapi keris adalah wujud konkret dari kekuasaan itu sendiri. (Putra, 2016, p. 42). Keris juga merupakan ageman bagi laki-laki dan tentu tidak diperuntukkan bagi perempuan. Kedua, permasalahan atas penghapusan gelar 
Khalifatullah yang bukanlah tanpa makna. Gelar ini berarti bentuk tanggung jawab sang raja di hadapan Allah SWT selama memimpin di bumi. Selain itu, gelar ini merupakan jati diri seorang raja yang bernafaskan Islam. Dengan demikian, jika merujuk pada asas kepemimpinan Islam, maka seorang pemimpin atau raja adalah laki-laki.

\section{Wacana "Raja Perempuan" dan Politik Kekuasaan}

Sepanjang 2015 Sultan HB X telah mengeluarkan Sabda Raja sebanyak empat kali. Sabda yang dikeluarkan oleh sultan tersebut berkaitan dengan persoalan suksesi di Keraton Yogyakarta. Pada 6 Maret 2015, masyarakat Yogyakarta dikagetkan dengan Sabdatama Sultan HB X yang merupakan kali kedua sang sultan mengemukakan sabda. Pada Sabdatama pertama, sultan mengeluarkan titah sebagai bentuk tanggapan atas polemik pembahasan Rancangan Undang-Undang Keistimewaan (RUUK) Yogyakarta. Sementara itu, Sabdatama kedua, adalah tanggapan Sultan HB X atas penggodokan rancangan Perdais Yogyakarta di DPRD DIY yang tergolong panas (Putra, 2016, p. 1).

Pada 30 April 2015, Ngarsa Dalem kembali mengeluarkan sabda. Isi Sabda Raja kali ini antara lain, pertama, penyebutan Buwono yang diganti menjadi Bawono; kedua, gelar Khalifatullah seperti yang tertulis lengkap dalam gelar raja-raja sebelumnya dihilangkan; ketiga, penyebutan Kaping Sedoso diganti menjadi Kaping Sepuluh; keempat, ada penambahan gelar Suryaning Mataram. Maka dari itu Sultan HB X juga mengubah gelarnya, dari yang awalnya bergelar Ngarso Dalem Sampeyan Dalem Ingkang Sinuwun Kanjeng Sultan Hamengku Buwono Senopati Ing Ngalogo Ngabdurrahman Sayyidin Panotogomo Khalifatullah Ingkang Jumeneg Kaping Sedoso Ing Ngayogyakarta Hadiningrat, berubah menjadi Ngarso Dalem Sampeyan Dalem Ingkang Sinuwun Sri Sultan Hamengku Buwono Ingkang Jumeneng Kasepuluh Suryaning Mataram Senopati Ing Ngalogo Langgeng Ing Bawono Langgeng, Langgeng Ing Tata Panotogomo.

Tidak lama kemudian, hanya berselang lima hari, Sultan HB X kembali bersabda. Pada 5 Mei 2015, Sultan HB X mengeluarkan Dhawuh Raja yang mengangkat G.K.R. Pembayun sebagai Putri Mahkota. Sebagai penanda pengangkatannya, G.K.R. Pembayun memperoleh gelar baru, yaitu Gusti Kanjeng Ratu Mangkubumi Hamemayu Hayuning Bawono Langgeng Ing Mataram. Dhawuh Raja atau Sabda Raja tersebut sontak membuat gaduh politik internal keraton. G.B.P.H. Yudhaningrat yang pada saat Sabdatama masih bersikap tenang, mendadak bersuara lantang menolak kedua sabda tersebut. Begitu juga adik-adik Sultan HB X lainnya, seperti G.B.P.H. Prabukusumo dan K.G.P.H. Hadiwinoto yang menganggap titah Sultan HB X melanggar Paugeran Keraton (Putra, 2016, p. 6).

Suhu politik yang terus naik juga merupakan dampak dari pemberitaan media massa yang terlalu masif, sehingga memunculkan banyak tanggapan dan komentar. Wacana raja perempuan ini juga menjadikan kerabat keraton Yogyakarta tercpecah. Perubahan Paugeran Keraton dalam persoalan pengaturan suksesi raja diduga akan menimbulkan goncangan yang besar. Sebab, perubahan gender raja akan berakibat pada perubahan tata nilai dan sistem ideologi yang dianut keraton. Sementara itu, 
keraton mengemban misi pengayoman bagi seluruh masyarakat (Harjono, 2011, p. 8). Pengaturan mekanisme suksesi di Keraton Yogyakarta sudah paten, yaitu Fiqh Islam dalam hukum khilafah. Al-Mulk (raja) dalam konsep ini adalah seorang laki-laki, sehingga kontradiksi wacana raja perempuan dikhawatirkan akan menyebabkan disharmoni sosial bagi Yogyakarta itu sendiri.

Keluarga sultan, terutama adik-adiknya menilai bahwa langkah Sultan HB X keliru dan bertentangan dengan adat, dan aturan Keraton Yogyakarta. Oleh sebab itu, beberapa adik sultan berziarah ke makam leluhur memintakan maaf atas perilaku Sultan HB X yang dinilai melanggar adat istiadat. Mereka bahkan tidak hadir ketika Sultan HB X mengumumkan nama baru bagi putri sulungnya. Barangkali itu merupakan bentuk protes terhadap kebijakan sultan. Namun demikian, pergantian nama ini tetap berlangsung dan menjadi tanda bahwa Pembayun akan menggantikan ayahnya menjadi sultan ke-sebelas yang bertahta di Yogyakarta (Kedaulatan Rakyat, 7 Mei 2015).

\section{Simpulan}

Kondisi yang dialami Yogyakarta saat ini persis pernah terjadi seperti yang dialami oleh Sri Sultan HB V menjelang suksesi kekuasaannya. Sultan HB V tidak memiliki anak laki-laki yang dapat menggantikannya. Semua anaknya perempuan, sehingga adik kandungnyalah yang menggantikan sang sultan. Akhirnya, Sultan HB VI bertahta menggantikan kakaknya yang wafat di usia cukup muda.

Belajar dari sejarah memang bukan hal mudah. Perubahan dan perputaran kehidupan terus terjadi. Apabila Sultan HB X mengikuti Paugeran Keraton, maka seharusnya ia mewariskan tahtanya kepada sang adik. Akan tetapi, semuanya berbeda, ketika paugeran bukanlah tonggak utama dalam pengambilan keputusan, maka hal di luar aturan pun dapat terjadi. Sabdatama dan Sabda Raja yang diterbitkan Sultan HB X bukan merupakan sumber hukum tata negara, baik dilihat dari segi formal maupun materiil. Hal itu karena isi dari Sabdatama dan Sabda Raja sampai saat ini belum sepenuhnya diakui oleh Pemerintah DIY dan masyarakat Yogyakarta, sehingga dianggap tidak memiliki legitimasi. Oleh sebab itu, menurut penulis, Sultan HB X sebaiknya meminta pendapat rakyat terlebih dahulu, apakah rakyat menghendaki perubahan UUK (Undang-undang Keistimewaan) seperti isi dari Sabdatama dan Sabda Raja atau tetap seperti apa yang sekarang sudah ditentukan dalam UUK. Keistimewaan yang dimiliki DIY bukannya tanpa batasan-batasan konstitusional, apalagi hanya ditentukan oleh satu orang, tetapi pemerintahan yang demokratis menghendaki dukungan dari segenap lapisan masyarakat.

\section{Referensi}

Berlian, S. (2002). “Legitimasi dan suksesi (studi tentang dasar hubungan rakyat dan penguasa dalam sejarah politik Jawa abad XV-XVI) (Tesis). Universitas Gadjah Mada, Yogyakarta.

Carey, Peter (terjemahan) (1985). Asal-usul Perang Jawa: pemberontakan Sepoy dan lukisan Raden Salen. Jakarta: Pustaka Azet. 
Darmasastri, Hayu A. (2006). Tradisi militer di kerajaan Jawa: Prajurit wanita di Kasultanan Yogyakarta masa Sultan Hamengkubuwono II 1767-1830 (Tesis). Universitas Gadjah Mada, Yogyakarta.

Dewi, Kurniawati H. (2017). Pegangkatan putri mahkota dan indikasi pergeseran konsep kuasa Jawa: Analisis Pendahuluan. Jurnal Masyarakat E Budaya, 19 (1): 59-76.

Fuhaidah, U. (2015). Resistensi penobatan putri mahkota untuk Kasultanan Yogyakarta. Jurnal Esensia, 16 (2). 169-175.

Harjono, S. (2011). Konflik di seputar suksesi Raja Kraton Kasultanan Ngayogyakarta Hadiningrat: Dulu, kini serta konteks masa depan (Tesis). Universitas Gadjah Mada, Yogyakarta.

Houben, Vincent J. H. (2002). Keraton dan kompeni Surakarta dan Yogyakarta, 1830-1870. Yogyakarta: Bentang Budaya.

Https://tirto.id/mk-putuskan-sultan-perempuan-bisa-jadi-gubernur-diy-cvGN, diakses 17 Oktober 2018.

Https://www.kratonjogja.id/raja-raja/6/sri-sultan-hamengku-buwono-v, diakses pada 17 Oktober 2018.

Kedaulatan Rakyat, 7 Mei 2015.

Margana, et al. (2016). Sultan Hamengkubuwono VII dan Kedaton Ambarukmo, Yogyakarta: Dinas Kebudayaan DIY.

Moedjanto, G. (1987). Konsep kekuasaan Jawa: penerapannya oleh raja-raja Mataram, Yogyakarta: Kanisius.

Purwadi (2007). Sejarah raja-raja Jawa (sejarah kehidupan kraton dan perkembangannya di Jawa). Yogyakarta: Media Abadi.

Putra, Fajar R. (2016). Sikap Politik Media dalam Polemik Suksesi Raja Yogyakarta (Analisis Wacana Kritis terhadap Surat Kabar Harian Kedaulatan Rakyat Dalam Polemik Suksesi Kraton Yogyakarta) (Skripsi). Universitas Gadjah Mada, Yogyakarta.

Ricklefs, M. C. (2005). Sejarah Indonesia modern 1200-2004. Jakarta: PT Serambi Ilmu Semesta.

Sesana, R. (2010). Intrik politik dan pergantian tahta di Kasultanan Yogyakarta 18771921 (Tesis). Universitas Indonesia, Depok.

Soekanto (1952). Sekitar Jogjakarta. Yogyakarta: t.p.

Sumbogo, R. M. Wibatsu Harianto (2000). Sri Sultan Hamengku Buwana II, Sultan Sepuh Hambangun Tapa. Yogyakarta: Mandara Giri Mataram.

Supariadi (1998). Surakarta Masa Pemerintahan Sunan Pakubuwono IV 1788-1820 Priyayi dan Kyai pada Masa Transisi Kolonial (Tesis). Universitas Gadjah Mada, Yogyakarta. 